\title{
Health concerns among waste collectors during pandemic crisis
}

\author{
Qing Ye ${ }^{1,3,2} \cdot$ Fahad Asmi $^{1}$ (D) $\cdot$ Muhammad Azfar Anwar ${ }^{4,5} \cdot$ Rongting Zhou $^{1,3} \cdot$ Ahmad Nabeel Siddiquei $^{6}$
}

Received: 10 June 2021 / Accepted: 17 August 2021 / Published online: 27 August 2021

(C) The Author(s), under exclusive licence to Springer-Verlag GmbH Germany, part of Springer Nature 2021

\begin{abstract}
The COVID-19 pandemic has negatively affected the economic, social, and psychological aspects globally. COVID-19 can possibly spread through municipal solid waste (MSW) if it is collected, bagged, transported, and disposed inappropriately. Such situation has posed significant challenges to MSW management (MSWM), which has led waste personnel under massive pressure. This study aims to examine the health-protective behavior of sanitation workers/MSW collectors (MSWCs) during the COVID-19 crisis. Quantitative data were collected by using a self-administered survey from 418 MSWCs working in Mainland China. The study extended the traditional health-belief model and proposed education and training as a facet of the behavioral model. Result showed that education and training were a significant predictor of health-protective behavior. Moreover, the moderating incremental influence of regulative assistance significantly affected the behavioral mapping of MSWCs. This study contributes to the literature by mapping the concerns, risks, and challenges experienced by MSWCs in times of a health crisis. Policymakers should specially consider the safety and hygiene concerns of frontline workforce in the whole chain of waste management (including the outsourced operations of MSWM). Lastly, the adoption of smart communication with the frontline workforce (i.e., MSWCs) is in dire need to maintain trust and avoid rumors and misconceptions during the time of a pandemic situation.
\end{abstract}

Keywords Waste collector · COVID-19 $\cdot$ China $\cdot$ Health belief model $\cdot$ Education and training $\cdot$ Task self-efficacy

\section{Introduction}

A respiratory system infection caused by coronavirus, which was officially named coronavirus disease 2019 (COVID-19) on February 11, 2020, by the WHO (2020), has posed a global crisis. Many countries have been forced to mandate lockdown as a measure to prevent the spread of COVID-19 (Haque et al.

Responsible Editor: Lotfi Aleya

Fahad Asmi

fasmie@ustc.edu.cn

Muhammad Azfar Anwar

azfar@ustc.edu.cn

1 University of Science and Technology of China, Hefei, Anhui, China

2 Fuyang Normal University, Fuyang, China

3 Key Laboratory of Immersive Media Technology (Wanxin Media), Ministry of Culture and Tourism, Hefei, Anhui, China

4 Shenzhen University, Shenzhen, China

5 COMSATS University Islamabad, Vehari, Pakistan

6 Bond University, Gold Coast, Australia
2021). The negative consequences of COVID-19 have spread across economic, social, and psychological aspects globally (Ahorsu et al. 2020). These consequences have a tremendous negative effect on human lives, financial markets, and the global economy (Hassan et al. 2021). One huge challenge that is relevant to people's lives is a sharp increase in the quantity and composition of municipal solid waste (MSW; Hantoko et al. 2021; Torkashvand et al. 2021).

Recently, the public concern on health has significantly overwhelmed people's attention on environmental carefulness around the world, which has led to environmental deteriorating effects to be ignored temporarily. First, the public have to use personal protective equipment (PPE), such as facemasks, to prevent infection and transmission of the COVID-19 effectively; however, millions of potentially contaminated masks are discarded every day around the world (Penteado and Marco 2021). Second, people have adapted the new normal with the spread of the COVID-19 pandemic, which has caused the complexities and difficulties of waste management (Torkashvand et al. 2021). The amount of online shopping and in-home cooking have increased sharply, which, in turn, have increased the amount of MSW (Yousefi et al. 2021). The increased demand for plastic-packaged food and groceries and 
the heavy usage of disposable supplies have also dramatically raised the amount of MSW, especially of plastic waste (Valizadeh and Mozafari 2021). In addition, people who are infected of the virus require home isolation rather than hospitalization, which produces hazardous waste daily (Penteado and Marco 2021). Haque et al. (2021) stated that one infected person produces $3.40 \mathrm{~kg}$ of generated hazardous waste daily. Municipal waste collection systems may not be able to handle a sudden increase in infectious waste. Lastly, the radical increase of medical waste has also brought heavy pressure on MSW management (MSWM). Consequently, the possibility of the transmission of COVID-19 has been intensified by the change of the quantity and composition of MSW.

The source of MSW basically consists of household solid waste (HSW; Hussein Abdel-Shafy and Mansour 2018), mainly including food, recyclable, and hazardous wastes and other solid waste (Wang et al. 2018). The MSWM system is composed of many key processes, such as waste production, collection, transportation, management, and disposal, which are strongly linked with socioeconomic aspects (Valizadeh and Mozafari 2021). However, the world has commonly faced environmental problems concerning MSWM (Tasi et al. 2020), especially in the most of the populous countries (Zolnikov et al. 2018). In addition to less systematic disposal dumping practices, administrative will and financial capacity are lacking, and the complex multidimensional system of MSWM is poorly handled in developing countries (Tasi et al. 2020). Although waste collectors (sanitation workers) have held an important role for protecting public health (Shin et al. 2019); they are potentially exposed to high risk of various occupational injuries and illnesses (Zolnikov et al. 2018; Ziaei et al. 2019). Penteado and Marco (2021) summarized that the potential occupational risks of waste workers include mechanical, ergonometric, chemical, biological, and social aspects. In comparison with developed countries, waste collectors have faced higher risk of occupational injuries in many developing regions. The reasons are as follows: high illiteracy rate of workers (Thakur et al. 2018), lack of standards and norms (Eskezia et al. 2016), shortage of protective gears (Ziaei et al. 2018), and lack of basic facilitating conditions (Salve et al. 2020). Moreover, Mol et al. (2017) argued that the factors that affect the rates of waste workers' accidents include lack of proper training, negligence of normal work routine, and informality of the profession. The advent of COVID-19 has aggravated the tension in MSWM, especially for waste workers. Research has reported that coronaviruses persist on different media and surfaces (e.g., metal, plastic, paper, ceramic, and glass) from $2 \mathrm{~h}$ to 9 days (Kampf et al. 2020), as well as $3 \mathrm{~h}$ in aerosols and 3-4 days in solid feces (Nghiem et al. 2020). Coronaviruses may exist on the whole spectrum of the MSW industry's activities. MSW must be collected, bagged, transported, and disposed appropriately to prevent the possible spread of COVID-19 through it. Such situation has posed significant challenges to MSWM, which has led to waste personnel being under massive pressure. The International Solid Waste Association (ISWA) emphasized that all governments should recognize the key role of waste workers and the waste sector in the period of epidemic. Waste workers are the second most important human shield to coronavirus, after health workers (ISWA 2020). Consequently, many governments have adopted socioeconomic support to waste workers. For example, workers involved in waste disposal sectors have been given the status of key workers to ensure safe schooling and care provision for their children and families by the government in the UK (Cabinet Office 2021).

However, ISWA highlighted that waste collection workers, as one of the most vulnerable parts of the population, have already been exposed in several health risks, including infections (ISWA 2020). Acharya et al. (2021) claimed that waste workers, as one of the frontline workers during the pandemic, have faced an alarming challenge of exposure to virus. Yousefi et al. (2021) also indicated that taking reasonable precautions and safety training for waste service personnel is necessary, especially the collection department in the COVID19 situation. During the COVID-19 outbreak, most governments and authorities' priorities have shifted toward public health protection from the viral infection rather than societal and environmental aspects (Haque et al. 2021). The situation is worse in developing countries because they lack personal protection equipment and clear guidelines to MSWM employees (Vaverková et al. 2021), awareness and campaign programs from the government (Acharya et al. 2021), and timely and effective training (Ganguly and Chakraborty 2021).

In the perspective of Mainland China, MSWM has continuously reformed at the local and national levels for addressing the clean collection, transportation, and disposal of MSW (The brief list of reforms and reports in Mainland China is listed in Appendix A.). The Chinese government began to be concerned about waste collectors (sanitation workers) in 1992 when the State Council of the People's Republic of China launched a proposal to improve their working conditions, improve their wages and benefits, and solve their housing difficulties. However, waste collectors have been labeled as the crowd of low income, low education, and low skills under dangerous and poor working conditions (Wei 2017). Alarmingly, the role of MSW collectors (MSWCs) has been overlooked. Particularly, the authors collected 22 reports and reforms published by different governing institutions in Mainland China in the last 30 years. Among the 22, only eight documents addressed the role and concerns of waste collectors. However, none of them addressed the challenges related to the pandemic situation. Moreover, MSWM faces several problems because it is still reforming. According to a survey (Tencent 2020), there exists chaos in employee identity in 
MSWM, that is, the employment contract of respondents (waste collectors) includes dispatched workers $(57.5 \%)$, formal staff $(22.5 \%)$, temporary workers $(10 \%)$, and contract workers $(5 \%)$. They came from 20 sanitation companies, and many of them could not accurately tell the name of their companies. Moreover, as discussed above, the Chinese government also adopted strict martial laws to the public to prevent the spread of COVID-19 (Fanelli and Piazza 2020), which derived a large amount of MSW. Several studies have addressed COVID-19 and waste as a new challenge (Hantoko et al. 2021; Richter et al. 2021; Capoor and Parida 2021; Behera 2021). However, works on health-protective behavior of MSWCs in Mainland China are unavailable. Thus, the present study aims to underline the health-protective behaviors of MSWCs in Mainland China during the ongoing pandemic crisis and map MSWCs' concerns while being on the frontline and collecting waste. To achieve the current objective, we adapted the health belief model (HBM) and proposed its extension by including task/performance self-efficacy and the role of education and training as a construct. Moreover, institutional theory (regulative and normative assistance) was applied as a moderator variable to create a unique framework. The objective of this study is to propose implications that can help academicians, administrative authority, and policymakers to understand the stance of waste collectors and possible contributions while proposing any reform related to MSWM, especially in the case of a pandemic situation.

\section{Theoretical background and hypothesis building}

\section{HBM}

HBM originated from the perception or belief about diseases (Kocoglu-Tanyer et al. 2020), which was modified and revised through the psychological theories of motivation, cognition, and value expectation (Janz and Becker 1984; Rosenstock 1974). HBM indicates that individuals' health behaviors will be positively affected by subjective assessment (Straub and Leahy 2014). Investigation on HBM dated from Rosenstock's research (1966), who developed the model that explored why and under what circumstances individuals will take action to prevent illnesses (Carpenter 2010). In the classic view of HBM, it consists of four basic components, namely, perceived susceptibility and severity, barriers, and benefits (Jones et al. 2015). Rosenstock et al. (1988) argued that selfefficacy can play a critical role in HBM. However, Carpenter (2010) underlined that it has been ignored in the previous pool of HBM-related literature. Similar influential power of cues to action, which can have an internal or external influential role (i.e., normative and regulative, as suggested by Urban and
Kujinga (2017)), was also underlined by Champion and Skinner (2008).

The intensive use of HBM in recent times signifies its significance and meaningfulness in depicting public healthprotective behavior (Keren et al. 2021). It has been one of the most effective models for explaining disease prevention, symptom responses, and other health-related behaviors (Del Villar et al. 2017). HBM has also been applied in investigating diverse health-related behaviors (Mo et al. 2019), such as breast self-examination (Didarloo et al. 2017), dietary behaviors (Khoramabadi et al. 2016), predictors of adherence with home quarantine (Al-Sabbagh et al. 2021), and public perception and preparedness for COVID-19 (Jose et al. 2021). Therefore, the current study adopted HBM because of the following inter-construct relationships. First, a strong relationship exists between individuals' preventive or protective behaviors and their perceived sense of exposure. Second, the study extended the traditional HBM and proposed education and training as a facet of the behavioral model. Last, the current study adopted the moderating role of regulatory and normative assistance instead of cues to action, as they can affect individuals' final action. In the context of traditional HBM, hypotheses of perceived exposure, perceived threat, barriers of being protected, benefits of being protected, and modified self-efficacy (task/performance self-efficacy) were adopted in the case to map the perceived health-protective behavior of MSWCs.

\section{Perceived exposure}

MSWCs always try to protect their health, but they are exposed to a dangerous working environment. Madsen et al. (2016) found that exposure to microorganisms has been a serious health problem for garbage collectors. Some authors have indicated that exposure to air pollution harms the public's health (Radisic et al. 2016; Mirzaei-Alavijeh et al. 2020). Travaglio et al. (2021) identified that long-term exposure to poor air quality increases the risks of COVID-19 infection and mortality.

The current study applied perceived exposure adapted from perceived susceptibility. Perceived exposure can be defined as individuals subjectively assessing the risk and seriousness of disease or health problems. Somville et al. (2021) found that perceived exposure is generally high $(88 \%)$ in physicians in the time of COVID-19. MSWCs who are conscious of risk of exposure will adopt preventive measures actively. Therefore, this study indicates that MSWCs' health-protective behaviors are affected by their perceived exposure.

\section{Perceived threat}

Perceived threat defines individuals' perceived possible negative result caused by not observing healthy behaviors (Kwon 
and Ahn 2019), which are preliminary driven by the influence of perceived exposure and further lead to health-related behaviors, especially for increasing the motivation of taking precautionary measures (Jeong and Ham 2018; Tajeri Moghadam et al. 2020; Carico Jr et al. 2021). Thus, higher perceived threat indicates a higher likelihood of engagement in health-promoting behaviors (Jose et al. 2021). Siddiqui et al. (2016) found a higher level of preventive practices on dengue among people who have perceived threat on dengue. Yuen et al. (2020) also argued that individuals' perception of threat defines their protective behavior. Workers will act more actively to avoid possible negative results because of a higher perceived threat. Hence, the current study proposes that MSWCs' health-protective behaviors depend on their perception of threat.

\section{Barriers of being protected}

Barriers of being protected (perceived barriers) indicate that individuals subjectively assess the costs or obstacles of given health behaviors. In some context, the possibility of participation of individuals' health-promoting behaviors is obstructed by perceived barriers (Kwon and Ahn 2019). Simply stated, higher individuals' likelihood of engagement in behavior decreases because of higher perceived barriers (Carico Jr et al. 2021). Perceived barriers have been adopted as a key variable for forecasting wide health behaviors, which involve customers' use of menu labels (Jeong and Ham 2018), injury prevention (Gabriel et al. 2019), influenza vaccine acceptance (Hu et al. 2017), and home quarantine (Al-Sabbagh et al. 2021). Generally, although MSWCs recognize the necessity of given health behaviors, they have to give up or not take action because of the costs or obstacles of given health behaviors. For example, people cannot wear standard masks when the masks are unavailable or when they cannot afford them at an exorbitant price. Thus, waste collectors' perception of the barriers of being protected concludes their health-protective behaviors.

\section{Benefits of being protected}

Benefits of being protected (perceived benefits) refer to individuals' perception of the positive consequences or benefits by engaging in given health behaviors (Carico Jr et al. 2021). Perceived benefits have been commonly applied to study individuals' health-related behaviors in cases of breast selfexamination behavior (Didarloo et al. 2017), injury prevention (Gabriel et al. 2019), acceptance of vaccination (Hu et al. 2017; Mo et al. 2019; Kocoglu-Tanyer et al. 2020), and waste management (Khan et al. 2019). Moreover, Jose et al. (2021) indicated that perceived benefits in HBM show a significant association with behavioral changes. Notably, almost all people are enthusiastic about receiving benefits. In other words, people are willing to adopt special behaviors if they can perceive positive consequences or benefits by participating. Thus, we infer that MSWCs' health-protective behaviors depend on their perceived benefits.

\section{Task performance self-efficacy}

Self-efficacy is individuals' confidence concerning their ability to achieve a particular goal (Bandura 1978; Taylor and Betz 1983). It is an important factor when individuals assess and achieve goals, tasks, and challenges (Kröninger-Jungaberle and Grevenstein 2013). Carico Jr et al. 2021 indicated that perceived self-efficacy is crucial because people do not start what they feel they cannot achieve. Moreover, various extensions of basis requests have been required by many specialists; thus, the concept of self-efficacy has been extensively extended. Many of these extensions are related to individuals' health behaviors, such as preventive service use self-efficacy (Jacob et al. 2016), self-care self-efficacy (Eller et al. 2016), alcoholrefusal self-efficacy (Lee et al. 2020), and pain self-efficacy (Larowe et al. 2020). Wen et al. (2021) suggested that selfefficacy buffers students' stress during COVID-19. In the current study, the influence of task self-efficacy among MSWCs' health-protective behaviors is a novel contribution to the literature. Specifically, frontline workers' health-protective behaviors in case of any pandemic situation (or crisis) have never been researched before.

To address the remaining constructs of traditional HBM, the extension of the existing HBM has also been proposed by addressing the construct of education and training, especially in the context of MSWCs' health-protective behaviors while working on the frontline in the time of the ongoing pandemic situation. Furthermore, the current study adopted institutional theory to elaborate the effectiveness of cues on institutional and social grounds instead of generalizing cues only for support. The related hypotheses will be discussed in the following subsections.

\section{Proposed extension of HBM (education and training)}

The definition of education can be understood as transmission processes in which accumulated information, knowledge, understanding, attitudes, values, skills, competencies, and behaviors are transmitted (ISCED 2011). Education and training can be formal or informal. Informal education and training include any organized and sustained learning activities that can be performed within and outside educational institutions and cater to people of all ages, such as adult literacy and work skills (UNESCO-UIS 2016) i.e. it can be done by using digital technologies and new media. From another perspective, learning can be defined as a change in behavior caused by an experience (De Houwer et al. 2013). Education and training seem to be an experience provider. Such condition, education, 
and training offer new experiences to learners that affect their behaviors. Research shows that education level had significantly affected the awareness of the $\mathrm{A}(\mathrm{H} 1 \mathrm{~N} 1)$ pdm09 pandemic, wherein women who had attended college were 77.8 times as likely as women with no formal education (Kouassi et al. 2012).

Moreover, $98.5 \%$ of community residents think that performing universal education of the prevention and treatment of public health emergencies is necessary (Zheng et al. 2020). Li et al. (2020) highlighted that health education and training are urgently required during the COVID-19 outbreak. Zhong et al. (2020) indicated that health education related to improving COVID-19 knowledge can contribute to community's optimistic attitudes and appropriate behaviors. Yue et al. (2020) emphasized that education programs about COVID-19 knowledge are extremely urgent for the general population, particularly for rural and undereducated residents. Educational interventions should be an important part of future outbreak responses (Kaim et al. 2020). The effect and value of education and training have been explored by many experts from different disciplines. Morony et al. (2018) presented that health education and training can empower adults' health management. Mackert et al. (2011) suggested that healthcare workers' health literacy and associated communication challenges can be enhanced by education and training. In addition, the role of education and training has been studied while mapping radiation protection (Higley 2017). Therefore, on the basis of the above literature in the "HBM" section and the "Proposed extension of HBM (education and training)" section, the following lists of hypotheses are considered in the current study.

H1(a and b): Perceived exposure influences the perceived task self-efficacy and perceived threat among MSWCs during the pandemic.

H2(a and b): MSWCs' education and training influence their perceived task self-efficacy and perceived threat during the pandemic.

H3 and H4: Perceived threat and task self-efficacy among MSWCs influence their health-protective behavior during the pandemic.

H5 and H6: Benefits and barriers of being protected while collecting waste during the pandemic influence the health-protective behavior of MSWCs.

\section{Role of perceived threat and task self-efficacy as mediators}

The literature has examined perceived threat/risk as a moderator (Champion and Skinner 2003) and a mediator (Jones et al. 2015) in the context of HBM. In the current study, the extension of HBM is distinctively proposed by adding the role of education and training. Moreover, it depicts a sociopsychological behavioral mapping in the time of the pandemic. In the same manner, self-efficacy has been tested as a mediator while mapping persuasive behavior modeling (Chen et al. 2015) and understanding self-regulated learning behaviors (Alghamdi et al. 2020). Furthermore, studies in organizational settings have underlined the role of task self-efficacy on performance (Wang and Hsu 2014). Thus, on the basis of the supporting constructs' behavior in the literature, we examine the mediating role of perceived threat and task self-efficacy on the health-protective behavior of MSWCs during the ongoing pandemic crisis. Particularly, we propose the following related hypotheses.

H7: As constructs, perceived task self-efficacy and perceived threat mediate the relationship between education and training and perceived health-protective behavior of MSWCs during the pandemic.

H8: As constructs, perceived task self-efficacy and perceived threat mediate the relationship between perceived exposure and perceived health-protective behavior of MSWCs during the pandemic.

\section{Regulatory and normative assistance}

Institutions regulate the society (North 1990); they can be a formal set of rules, regulations, norms, values, and taken-forgranted assumptions (Scott 2002; Bruton et al. 2010). Institutional environment/pressure can considerably affect organizational (DiMaggio and Powell 1991) and individual behaviors (Griffiths et al. 2013). Institutional theory has been used as a key factor in predicting organizational and individual behaviors in several studies. Seelos et al. (2011) explained that the regulatory environment is the formal rules and regulations that conduct individual behaviors. Such an environment includes rewards and punishments (Valdez and Richardson 2013). Urban and Kujinga (2017) found that the regulatory environment considerably affects workforce's intentions. Furthermore, the regulatory environment has been confirmed as a positive factor for individuals' responsible and conscious behaviors (Zhang et al. 2019; Ye et al. 2020a, 2020b) and has remarkably played its role in HSW-related studies (Ye et al. 2020b).

Conversely, normative environment can be defined as the individuals' perception of social pressure that normalizes their behavior (Ma et al. 2018). Such an environment includes normative beliefs. Normative beliefs conduct individuals' given behaviors, which are based on the approval or disapproval of important referent individuals or groups (Ajzen 1991). Wu et al. (2019) indicated that individuals' intention and behavior are significantly affected by the normative environment. Bruton et al. (2010) reported that the normative 
environment establishes the social value that guides individuals' behavior. Particularly, a significant relationship exists between normative beliefs with individuals' intention and behavior in a collectivist society (Furnham et al. 2012; Wu and Chen 2014; Shi et al. 2017). Therefore, in the current research setting, the following hypotheses are proposed for the study.

- H9: Regulatory assistance moderates the relationship of exogenous factors (perceived threat and task self-efficacy) with the endogenous factor (perceived health-protective behavior) in the case of MSWCs during the pandemic.

- H10: Normative assistance moderates the relationship of exogenous factors (perceived threat and task self-efficacy) with the endogenous factor (perceived health-protective behavior) in the case of MSWCs during the pandemic.

The graphical representation of the proposed model of the research is shown in Fig. 1.

\section{Methodology}

\section{Sample and procedure}

We conducted a questionnaire-based online survey and collected responses from frontline MSWCs. To access the potential respondents, we contacted the concerned public office and gained necessary approval. The public office helped us approach the frontline MSWCs who are affiliated with two private cleaning companies, namely, Anhui Hongyang Environmental Greening Management Co., Ltd. and Hubei Jiashicheng Environmental Protection Technology Co., Ltd. We requested the representatives of both enterprises to help in collecting data from Anhui and Henan Provinces (in Mainland China). The involvement of enterprises (private firms) for frontline MSW collection is the part of national policy for MSWM since 2004, as listed in Appendix A. The principal researcher physically visited each participating organization multiple times to meet the potential participants and requested them to participate in the online survey (through www.wjx. $\mathrm{cn})$. Ethical and health-related clearances were obtained from multiple institutions involved. First, ethical clearance was requested from the affiliated institution (Department of Science and Technology of Communication, University of Science and Technology of China) to assure data anonymity and adopt all concerned standard operating procedures. Second, we requested permission and assistance from the concerned representative of the "Urban Management and Law Enforcement" (UMALE) to collect data for the academic research. After the ethical approval, UMALE forwarded and helped us coordinate with the two concerned private cleaning companies stated above. After having the ethical approval from each of the involved public and private institutions, data were collected officially.

To increase the response rate, we kept revisiting the concerned offices. To maximize the response rate, a lucky draw (red envelope) was offered to respondents who completed the survey, which helped create a shared "buzz" about participating. Data collection was performed from the first week of March 2020 until the end of the second week of August 2020. Each questionnaire included a cover page that explained the brief objective of the study, the voluntary nature of the survey, and assurance of anonymity and confidentiality. We also provided the contact details of the principal researcher in case the respondents have any questions or inquiries about the study. We approached nearly 700 frontline workforce

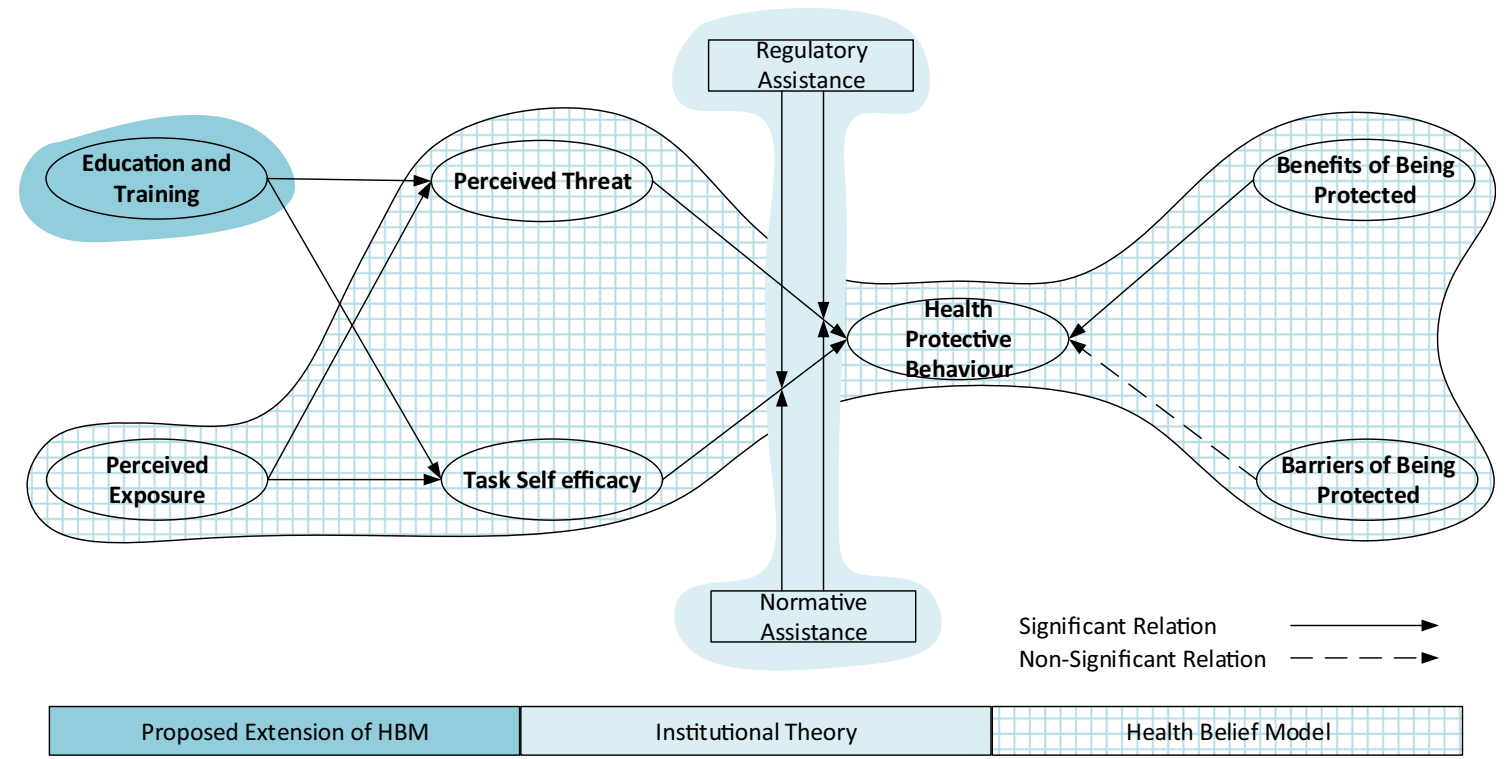

Fig. 1 Graphical representation of the proposed model 
(MSWCs) associated with the waste management firms and received 418 completed and usable questionnaires, making an overall response rate of $59.71 \%$. We discarded 37 questionnaires because of invalid or incomplete responses. We examined the nonresponse bias in our dataset by comparing the personal and professional attributes of early respondents (those who participated in March 2020) versus late respondents. Using $t$-test, we did not find any significant differences between both sets of respondents (early versus late respondents).

\section{Measurement instrument}

We used well-established scales to measure the primary constructs of the study. The questionnaire had two sections. The first section comprised of all items measuring independent, mediating, moderating, and dependent variables. The second section captured personal and professional attributes of the participants, including age, gender, employment status, and years of work experience. The questionnaires were conducted in the Chinese language for the ease of the participants' understanding. However, to confirm the validity and reliability of the questionnaire, we used a back-translation method, as suggested by Brislin (1970). In this method, we initially translated the English version of the questionnaire to the Chinese version via a professional language translator. Then, we translated the Chinese version of the questionnaire back to the English version by using the services of a different language expert. The two English versions of the questionnaire were then compared by a native English speaker, who confirmed the equivalence of both versions. Finally, the Chinese version of the questionnaire was pretested on a diverse group of individuals belonging to different age, gender, education, and employment categories. We identified small glitches and performed minor modifications to the wording, content, and overall structure of the questionnaire and cover letter. Thus, we confirmed that all items were appropriate and relevant to the corresponding variables, ensuring content validity and reliability. Table 1 presents the English and Chinese versions of the measurement items. All items were rated by the respondents on a 5-point scale, ranging from 1 (strongly disagree) to 5 (strongly agree).

\section{Common method bias}

Although the objective was to assess the perception of MSWCs, we collected data from a single source. To assess whether common method bias would be a significant issue in our collected sample, we used the well-established and robust Harman's single-factor test. We performed exploratory factor analysis on our data, which indicated that the largest single factor explained $29.67 \%$ of the total variance. No single factor captured the major proportion of the total variance. To verify the external validity of the collected data, common latent factor was also computed, following Keren et al. (2021). Particularly, no significant difference was found in the standard regression scores above the upper cutoff of 0.200 recorded in the cases of absence and presence of CLF. Thus, the research eliminated the risk of common method bias. In terms of age, approximately $17 \%$ of the participants were under 25 years old, $23 \%$ were between 25 and 35 years old, $38 \%$ were between 35 and 45 years old, and $22 \%$ were above 45 years old. Approximately $87 \%$ of the respondents were male, whereas $13 \%$ were female. In terms of work experience, approximately $21 \%$ of the respondents had less than 1 year of work experience, $36 \%$ had 1-3 years of work experience, $27 \%$ had 3-5 years of work experience, and $16 \%$ had more than 5 years of work experience. Overall, our sample presents a satisfactory representation of employees with diverse personal and professional attributes. Table 2 presents the descriptive profile of the respondents.

The table shows the sample distribution of 418 waste collectors investigated in this study.

\section{Findings}

\section{Measurement model}

In the next step, we assessed the quality of data in the measurement model. We used four robust criteria to evaluate the measurement model: (i) construct reliability, (ii) convergent validity, (iii) discriminant validity, and (iv) nomological validity. The tabular representation of the measurement model is listed in Appendix C. Specifically, all four criteria were used to assess the measurement model. First, construct reliability was evaluated using conventional and established Cronbach's $\alpha$. All constructs showed satisfactory reliability with the values above the minimum cutoff criteria of 0.70 . Among all constructs, health-protective behavior showed the highest relatability with $\alpha=0.95$, whereas normative environment demonstrated the lowest but acceptable reliability with $\alpha=$ 0.71 . The convergent, discriminant, and nomological validities were further examined for construct validity. Regarding convergent validity, we found satisfactory results for composite reliability (CR) and average variance extracted (AVE) of all the surveyed constructs. The CR of all constructs were beyond the threshold value of 0.70 , with healthprotective behavior having the highest $\mathrm{CR}(0.95)$ and normative environment varying the low but acceptable CR (0.79). The standard loadings of all items were higher than the desired threshold of 0.7 and significant at 0.001 , which indicated a good convergent validity, as listed in Appendix C-1.

Regarding discriminant and nomological validities, we estimated the AVE and Dijkstra-Henseler's rho $\rho_{A}$ 
Table 1 Instruments adapted in the current study (English version).

\begin{tabular}{|c|c|c|}
\hline Constructs & Items & Sources \\
\hline Education and training & $\begin{array}{l}\text { In the context of waste sorting and collecting process } \\
\text { 1. Education and training gave me confidence } \\
\text { 2. Education and training improved my performance } \\
\text { 3. Education and training are knowledgeable and assist me in understanding new } \\
\text { tasks }\end{array}$ & Zulfiqar and Asmi (2019) \\
\hline Perceived exposure & $\begin{array}{l}\text { 1. I will likely be infected with COVID-19 } \\
\text { 2. I believe that COVID-19 is a severe health problem } \\
\text { 3. I feel that I will get COVID-19 sometime during the pandemic }\end{array}$ & Champion (1999) \\
\hline Perceived threat & $\begin{array}{l}\text { 1. My chance of getting exposed to COVID-19 is high if I do not perform safety } \\
\text { behavior } \\
\text { 2. I will be more likely to be exposed to COVID-19 if I do not perform safety } \\
\text { behavior } \\
\text { 3. The thought of being exposed to COVID-19 scares me }\end{array}$ & Yuen et al. (2020) \\
\hline $\begin{array}{l}\text { Performance/task } \\
\text { self-efficacy }\end{array}$ & $\begin{array}{l}\text { 1. I am sure that I can learn about any new task in my job } \\
\text { 2. I have high self-confidence when it comes to understanding new tasks } \\
\text { 3. Even before I begin to listen or get involved in any new task on the job, I feel } \\
\text { confident that I can understand it }\end{array}$ & $\begin{array}{l}\text { Nietfeld et al. (2006); White et al. } \\
\text { (2019) }\end{array}$ \\
\hline $\begin{array}{l}\text { Health-protective behavior } \\
\text { while collecting waste }\end{array}$ & $\begin{array}{l}\text { 1. I follow all safety procedures (which are necessary or advised by the health and } \\
\text { safety department) at any cost } \\
\text { 2. I follow safety rules that I think are necessary or advised by the health and safety } \\
\text { department } \\
\text { 3. I try my best to get every information necessary to protect myself }\end{array}$ & Yuen et al. (2020) \\
\hline Regulatory assistance & $\begin{array}{l}\text { Relevant government departments actively... } \\
\text { 1. ... emphasized that safety precautions are important to be taken while dealing } \\
\text { with COVID-19 during waste collection } \\
\text { 2. ... communicated about the advantages of adopting safety measures (i.e., by } \\
\text { sharing best practices). } \\
\text { 3. ... working to control the spread of COVID-19 }\end{array}$ & Tajeri Moghadam et al. (2020) \\
\hline Normative assistance & $\begin{array}{l}\text { While communicating with my colleagues, I have heard about the... } \\
\text { 1. ... important safety precautions to be taken while dealing with the current } \\
\text { emergency } \\
\text { 2. ... advantages of adopting safety measures while dealing with the current } \\
\text { emergency } \\
\text { 3. ... encouragements to adopt precautionary measures }\end{array}$ & Tajeri Moghadam et al. (2020) \\
\hline Barriers of being protected & $\begin{array}{l}\text { 1. To stay at safe enough space keeps me restricted to perform effectively } \\
\text { 2. To stay at safe enough space brings me psychological pressure } \\
\text { 3. It is very hard for me to perform standard operation procedures with } \\
\text { precautionary measures }\end{array}$ & Champion (1999) \\
\hline Benefits of being protected & $\begin{array}{l}\text { 1. I believe that by taking precautionary measures, as suggested by health experts, } \\
\text { can prevent serious outcomes } \\
\text { 2. In the case of collecting and sorting waste, adopting safety measures (i.e., using } \\
\text { mask and gloves) would protect me from COVID-19 }\end{array}$ & $\begin{array}{l}\text { Fallah Zavareh et al. (2018); Tajeri } \\
\text { Moghadam et al. (2020) }\end{array}$ \\
\hline
\end{tabular}

Table 2 Descriptive profile of the respondents.

\begin{tabular}{llll}
\hline Descriptive & Detail & Frequency & Percentage \\
\hline Age & Under 25 & 71 & $16.99 \%$ \\
& $25-35$ & 96 & $22.96 \%$ \\
& $35-45$ & 158 & $37.80 \%$ \\
Gender & Above 45 & 93 & $22.25 \%$ \\
Work experience & Male & 363 & $86.84 \%$ \\
& Female & 55 & $13.16 \%$ \\
& Less than 1 year & 87 & $20.81 \%$ \\
& 1-3 years & 149 & $35.65 \%$ \\
& 3-5 years & 113 & $27.03 \%$ \\
& More than 5 years & 69 & $16.51 \%$ \\
\hline
\end{tabular}

of the study constructs. All primary constructs showed AVE above the recommended cutoff criteria of 0.50 . Discriminant validity was evaluated in two steps. The Fornell and Larcker criterion was calculated, in which the square root of the AVEs noted was greater than the inter-construct correlations (Hair et al. 2010). The results in the tabular format are listed in Appendix C-2. The values of the heterotrait-monotrait ratio of correlations were also calculated, considering the threshold of 0.90, as listed in Appendix C-2 (Henseler et al. 2014). These results provided sufficient evidence of discriminant validity for these constructs. Multi-collinearity was also calculated by variance inflation among items of each of the constructs. All VIF scores were below the 
upper cutoff value of 3 (Hair et al. 2010). The tabular output is listed in Appendix C-3.

\section{Structural model: direct and indirect effects}

The structured model was tested using partial least squares (PLS), as a technique in ADANCO 2.0.1. The model fitness scores for the saturated and estimated models, which satisfy the cutoff suggested by Henseler (2017), are shown in Table 3 .

$S R M R$ standardized root mean square residual, $d U L S$ unweighted least squares discrepancy, $d G$ geodesic discrepancy, HI95 95\% percentile, HI99 99\% percentile

Direct effects In the next step, we used ADANCO 2.0.1 with bootstrapping to test the direct effect hypothesis in the proposed model. Moreover, the effect size of each of the hypotheses was calculated to measure its significance. Particularly, the effect size of each hypothesis scored as weak, moderate, or high at cutoff values of $0.02,0.15$, and 0.35 , respectively, as suggested by Hanel and Mehler (2019). Only the hypotheses addressing the influence of education and training on task selfefficacy were recorded with a weak effect and noted as insignificant. The tabular outcome with direct path analysis and effect size is listed in Appendix C-4. The variance explained $\left(R^{2}\right)$ by perceived threat, task self-efficacy, and perceived health-protective behavior was calculated as $0.823,0.741$, and 0.885 , respectively.

The results of direct effect hypothesis are as follows. Regarding H1(a and b), education and training had a positive and significant link with task self-efficacy $(\beta=0.31, p \leq 0.01)$ and perceived threat $(\beta=0.17, p \leq 0.01)$. A similar trend of findings has also been noted in the existing pool of literature (Boswell et al. 2019; Shin et al. 2019). Thus, H1 ( $a$ and b) were accepted. Regarding H2(a and b), perceived exposure was positively and significantly associated with task self-efficacy ( $\beta=0.62, p \leq 0.01)$ and perceived threat $(\beta=0.78, p \leq 0.01)$. This trend of relationship has also been observed in the literature (Janmaimool 2017; Yuen et al. 2020). Therefore, H2(a and b) were supported. Regarding $\mathrm{H} 3$ and $\mathrm{H} 4$, a positive and significant direct relationship was observed between perceived threat and health-protective behavior $(\beta=0.72, p \leq$ $0.01)$ and between task self-efficacy and health-protective behavior $(\beta=0.24, p \leq 0.01)$. Hence, $\mathrm{H} 3$ and $\mathrm{H} 4$ were accepted. The mapping of the potential inference of perceived benefits (H5) and perceived barriers (H6) of being protective showed a positive and significant direct association between perceived benefits of being protective and health-protective behavior $(\beta=0.11, p \leq 0.05)$. However, in the case of perceived barriers (H6), an insignificant relationship was observed ( $\beta=0.004, p \geq 0.05$ ). Similar trend of research findings have also been observed in the literature ( $\mathrm{Hu}$ et al. 2017; Razmara et al. 2018; Tajeri Moghadam et al. 2020). Moreover, the control variables (i.e., age, gender, and experience) were noted as insignificant in the current study. Specifically, in terms of elder age (above 45), the relationship from $\mathrm{BaBP}$ to HPB was observed as significant $(\beta=0.204)$; in the case of the overall model, it is nearly neglectable. BeBP was also recorded as strengthened $(\beta=0.251)$; in the case of the overall model, it was recorded as weak. Thus, among elder people (above 45), BaBP and BeBP were recorded as dominating constructs to define HPB in comparison with the response trends from the overall population.

Mediation (indirect effects) and moderation We used two complementary approaches to test the mediating effects of perceived threat and task self-efficacy among MSWCs in the relationship between exogenous factors (education and training and perceived exposure) and endogenous factor (health-protective behavior). Particularly, the method recommended by Preacher and Hayes (2008) was adopted, followed by that of Baron and Kenny (1986), to compute the mediation effect. The tabular and narrative detail of the mediation process conducted is presented in Appendix C-5. The findings concluded that perceived threat and task self-efficacy partially mediate (in serial mediation) the proposed exogenous factors (education and training and perceived exposure) and endogenous factor (health-protective behavior). Overall, the empirical results largely support our theoretical propositions.

In the final step, we tested the moderating role of regulatory and normative assistance in the relationship of the proposed mediators (perceived threat and task selfefficacy) with the endogenous factor (health-protective behavior), which are noted as H9a, H9b, H10a, and H10b. We used hierarchical regression to test the moderation hypothesis, as suggested by Qing et al. (2020). The tabular and narrative explanation of the moderation analysis is listed in Appendix C-6. Figure 2 shows the interaction plot for each of the moderation effect, as proposed in the "Theoretical

Table 3 Fitness measured through PLS (in ADANCO 2.0.1).

\begin{tabular}{|c|c|c|c|c|c|c|c|c|}
\hline & Saturated & Score & HI95 & HI99 & Estimated & Score & HI95 & HI99 \\
\hline SRMR & & 0.039 & 0.048 & 0.053 & & 0.042 & 0.052 & 0.058 \\
\hline dULS & & 0.688 & 0.809 & 0.993 & & 0.766 & 0.950 & 1.188 \\
\hline $\mathrm{dG}$ & & 0.403 & 0.618 & 0.785 & & 0.551 & 0.664 & .0821 \\
\hline
\end{tabular}



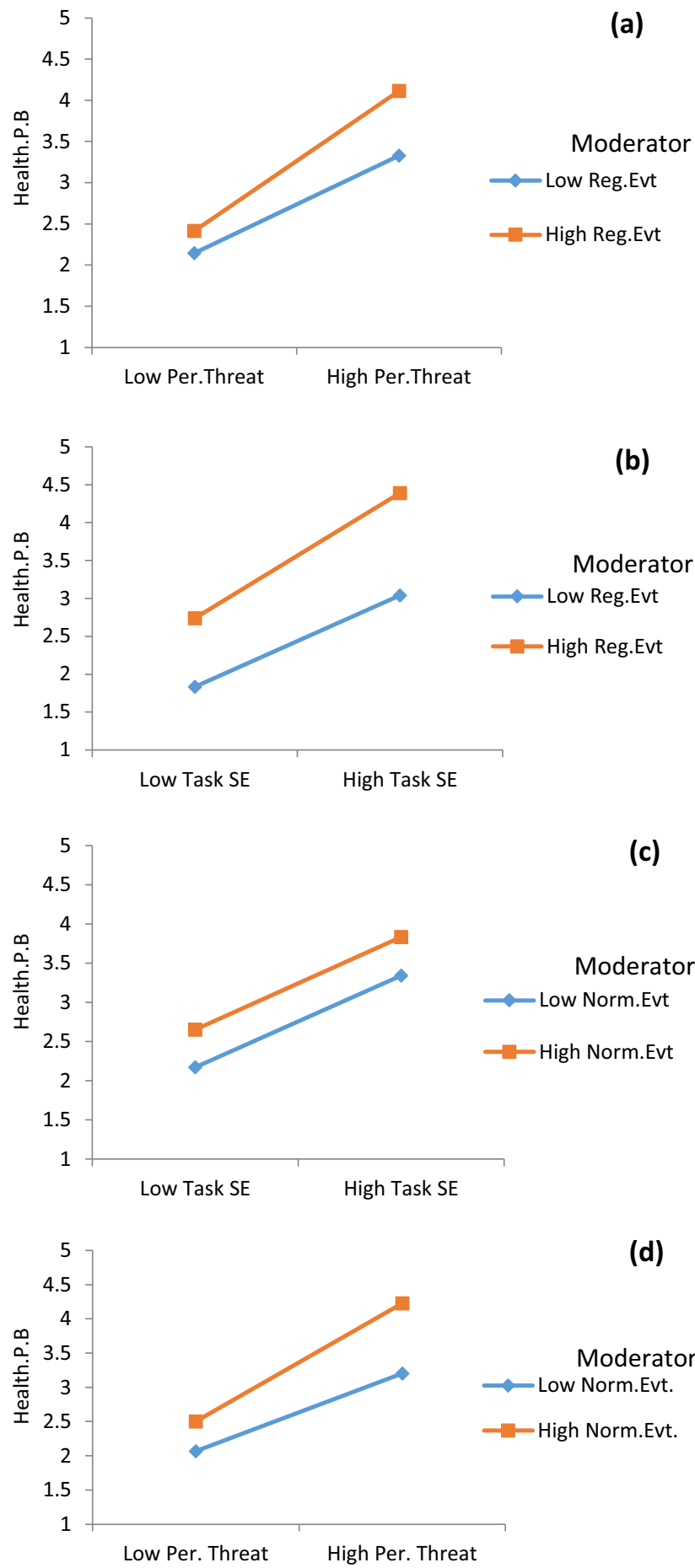

Fig. 2 a Interaction plots examining the moderating effect of H9(a) (regulatory assistance while mapping perceived threat over healthprotective behavior); b H9(b) (regulatory assistance while mapping task self-efficacy over health-protective behavior); c H10(a) (normative assistance while mapping perceived threat over health-protective behavior); and $\mathrm{d} \mathrm{H} 10$ (b) (normative assistance while mapping task self-efficacy over health-protective behavior).

background and hypothesis building" section. The findings conclude that the role of regulatory assistance is a more influential moderator than the role of normative assistance. Findings further highlighted the insignificant effect of normative assistance in the case of the relationship between task selfefficacy and health-protective behavior (in the time of pandemic), which can be an interesting finding.

\section{Discussion}

The current study extended HBM with the new variation of self-efficacy by proposing task/performance self-efficacy and proposed the extension by adding the role of education and training, which hold a significant explanatory power in the setting of the proposed model. Moreover, the strategic role of regulatory assistance was observed. The theoretical and practical implications of this study will be discussed in the following subsections.

\section{Theoretical implications}

The first theoretical contribution is that the study used education and training as an exogenous factor while mapping health-protected behavior in the perspective of $H B M$. Education can be considered information, knowledge, skills, competencies, and transitions. It includes not only formal education and training offered by formal educational institutions but also informal forms consisting of any organized and sustained learning activities on the job. The findings of our study are also supported by Davis et al. (2018), who highlighted that individuals' environmental health skills are significantly enhanced by education and training. Furthermore, education and training have been confirmed as a positive factor for preventing and reducing occupational injuries and illnesses among MSWCs (Bogale et al. 2014; Zolnikov et al. 2018; Shin et al. 2019; Kaim et al. 2020). As $\mathrm{Li}$ et al. (2020) indicated, health education and training are urgently required during the COVID-19 outbreak. Therefore, education and training should be applied as an exogenous factor to $H B M$ while studying any organizational setting to measure health-protective behavior during a pandemic situation. Particularly, the exogenous effect of education and training in the case of HBM can be noted as a unique contribution in terms of understanding (1) MSWCs' behavior, (2) circumstances in Mainland China, and (3) pandemic situations.

Second, HBM is one of the most useful theories that predict individuals' health-protective behaviors (Tajeri Moghadam et al. 2020), which has also been supported by the current study. The institutional theory has been adapted by emphasizing two principal pillars, regulative and normative pillars (Scott 2008), which significantly affect organizational (DiMaggio and Powell 1991) and individual (Griffiths et al. 2013) behaviors. The current study concluded that in 
comparison with normative assistance, the role of regulatory assistance is more significant and prominent while mapping MSWCs' health-protective behavior, which is accordance with the research of Al-sabbagh et al. (2021). In other words, the study concludes that the use of regulatory reform should be used more efficiently and effectively during the pandemic situation while understanding the health-protective behaviors of frontline workers (i.e., MSWCs). According to a press conference held on April 12, 2020 (SCIO 2020), the performance of MSWCs has excellently been acclaimed. The group has played an extremely critical role in epidemic prevention and control in China. They have not only performed their normal tasks well but have also undertaken emergency tasks, such as disinfection and sterilization on related places, management of public toilets in mobile cabin hospitals and transportation, and disposal of medical waste. The press conference also emphasized that a series of measures will be launched to look after and improve MSWCs' facilitating conditions, including physical and psychological health and welfare treatment and salary. The signal has been responded by governments at all levels and societies at all sectors. The current findings can predict the relatedness of the aforementioned secondary source of information.

Third, the reform, which outsources (marketization) public services, has been widely practiced by the Chinese government; one typical example is urban sanitation service. Sanitation enterprises have been established at Shenzhen in 1984. In 2017, most cities conducted outsourcing (marketization) of municipal sanitation (Li 2019). Notably, a landmark policy was implemented, namely, Guidelines of the General Office of the State Council on the Government's Purchase of Services from Social Forces (General Office of the State Council 2013), which accelerated the outsourcing (marketization) of municipal sanitation services. Municipal sanitation services have reformed more than 30 years; however, many problems have not been resolved, including the absence of public service responsibility, inefficiency of governmental supervision and contract (Huang 2012), incomplete contract signing system, and negative influence on the interests of sanitation workers (Li 2014). For example, an incomplete contract signing system has caused messy employment approaches, formal workers, contract workers, temporary workers, and dispatch laborers (leased workers) in one mechanism. In conclusion, local governments act as regulators, and sanitation enterprises perform tasks of municipal sanitations at most cities. This study suggests that the institution (government) must implement all health-related concerns and policies even for outsourced (marketization) firms. Thus, in case of any pandemic crisis, the workforce can gain confidence and support from the government in terms of accurate and reliable facilitating conditions.

Fourth, the study can also be noted as a valuable finding, because it can help formulate future strategies in case of any pandemic situation and design strategies for other frontline workers (including medical staff and law enforcement agencies). The study's conclusion of the weak role of the normative environment as a moderator also highlights the urgency to address the dynamics of the normative environment by academicians and policymakers, with the intention to transform this weak link into a valuable game changer by addressing stakeholders' interests and dynamics.

Lastly, in the current study, the influence of task selfefficacy among MSWCs' health-protective behavior is a novel contribution to the literature. Specifically, the health-protective behavior of frontline MSWCs in case of any pandemic situation (or crisis) has never been researched. This study is the first to use the mediating role of perceived threat and perceived task self-efficacy simultaneously in case of defining health-protective behavior while taking perceived exposure and workforce's education and training as exogenous factors. The partial mediating role of the proposed mediators signifies the role of proposed mediators in the case of examining MWSCs' health-protective behavior. Previously, healthrelated studies have mentioned the significant role of education and training to define perceived threat and self-efficacy. Similarly, perceived exposure has been studied to understand perceived threat and self-efficacy. However, none of the literature has taken both mediators simultaneously (in a serial or parallel manner). Thus, the current study is valuable as its underlining role of perceived threat and task self-efficacy as mediators and signifies its role in the time of crisis and future pandemic situation.

\section{Practical implications}

The first practical contribution of the study is mapping the stance and conditions of MSWCs under a pandemic situation. Notably, MSWCs are responsible for collecting, transporting, and processing of MSW. They have been a key part of protecting public health (Shin et al. 2019). The situation during COVID-19 can worsen; as a result, MSWCs have faced inconceivable dangers. The COVID-19 pandemic has caused an increase in the quantity and composition of MSW (Hantoko et al. 2021), which possibly leads to risk of spreading the virus in the process of waste management (Torkashvand et al. 2021). Therefore, the current initiative mapped the stance and condition of MSWCs during the pandemic, which is first of its kind.

Second, the result of the current study showed that during the COVID-19 outbreak, the influence of the normative environment is relatively weak among MSWCs. In other words, this study underlined the anxiety and fear among MSWCs, which were triggered by the workforce's perception of risks during the epidemic. The widespread outbreak of COVID-19 has led to psychological distress and mental illness of the public (Rajkumar 2020). The myths and misinformation 
related to COVID-19 have negatively affected epidemic prevention and control (Bao et al. 2020; Zandifar and Badrfam 2020). Fake news (incorrect news) on social media also negatively affect public health (Mian and Khan 2020). The current research findings suggest that governing institutions should have an official mode of communication with the workforce, which can provide authentic and reliable information communication. It can improve the trust of MSWCs over the institution. It can further provide two-way communication mode for the workforce, which indirectly improves the sense of social responsibility, sense of affection, and recover from distrust among stakeholders.

The last suggestion is to expand the role of governing institutions by providing adequate protective resources and equipment to adopt health-protective behavior among MSWCs. The integration of public and private organizations is evident in current practices. However, the outsourcing practice still places more emphasis on the efficacy and results. MSWM should be reformed, where private organizations should strictly adopt the economic and hygienic concerns of the workforce as recommended by governing institutions. For instance, the role of economic institutions is strongly correlated with the current pandemic crisis (Kinateder et al. 2021; Hassan et al. 2021). This recommendation can be achieved by adding strict requirements for private firms (enterprises) to train and provide facilitating conditions to each frontline MSWC for achieving each task. As indicated in Appendix A, reforms and reports addressing MSWCs' rights and facilitating conditions are limited and must thus be addressed in future policies and reforms by the governing institutions in Mainland China.

\section{Conclusion and future studies}

The environmental problem driven from MSWM is a global issue, especially in most of the developing countries. The COVID-19 pandemic has worsened the situation. The government and public concern on health has significantly overwhelmed people's attention on environmental carefulness around the world, which has led to environmental deteriorating effects to be ignored temporarily. As a result, the situation has caused in the complexities and difficulties of waste management. Especially, sanitation workers/MSWCs who are the second most important human shield to COVID-19 not only have faced work overload but have also been exposed to several health risks, including high risk of infections in the current pandemic situation.

The result showed that the moderating incremental influence of regulative assistance significantly affected the behavioral mapping of MSWCs. All governments should recognize the key role of waste workers and the waste sector in the period of an epidemic. Particularly, governing institutions should supply adequate PPE, offer professional training, and provide socioeconomic support (including for their children and families), such that MSWCs can adopt health-protective behaviors. In the case of China, MSWM includes public and private organizations (outsourcing), in which outsourcing practices still place more emphasis on efficacy and profit. In a time of pandemic, private organizations should strictly adopt economic and hygienic concerns on the workforce as recommended by governing institutions.

The persuasive behavioral psychological model of stimulus-organism-response can be adopted in future studies to underline the stressors and concerns of MSWCs. It can be further revised and improved by underlining the role of MSWCs' anxiety and dissatisfaction during a pandemic. The current study's initiative emphasized the role of task self-efficacy. The role of health self-efficacy and literacy can be adopted in future studies. The present study contacted the UMALE to request for permission and assistance to collect data for academic research. Future studies can underline the concerns and challenges of managerial staff and mid-level human resources to understand the challenges of MSW collection and management. Moreover, data collection was conducted using an online survey because of the requirements of epidemic prevention and control, which may have caused the older group of MSWCs to be overlooked. The demographic characteristics and primary goal of future studies can be set to underline the trend in behavior change in case of different age groups during any pandemic crisis. Lastly, hygiene and safety concerns can be compared between private and public sector stakeholders, given that frontline MSWCs are associated with enterprises (private firms).

Supplementary Information The online version contains supplementary material available at https://doi.org/10.1007/s11356-021-16071-y.

Author contribution Conceptualization, Rongting Zhou; formal analysis, Muhammad Azfar Anwar; funding acquisition, Fahad Asmi; investigation, Ahmad Nabeel Siddiquei; methodology, Fahad Asmi; software, Ahmad Nabeel Siddiquei; supervision, Fahad Asmi; validation, Muhammad Azfar Anwar; visualization, Fahad Asmi; writing (original draft), Ye Qing; writing (review and editing), Ye Qing

Funding The research was funded by the Key Laboratory of Immersive Media Technology (Anhui Xinhua Media Co, Ltd.), Ministry of Culture and Tourism, Hefei, China.

Availability of data and material Data will be available on reasonable request.

\section{Declarations Not applicable}

Ethics approval Ethical clearance from the ethical committee from the Department of Science and Technology of Communication, University of Science and Technology of China was provided. 
Consent to participate Informed consent was obtained from all individual participants included in the study (included in the cover letter of the questionnaire).

Consent for publication The authors affirm that respondents for the questionnaire survey provided informed consent for publication (included in the cover letter, and authors assured their identity to keep anonymous).

Conflict of interest The authors declare no competing interests.

\section{References}

Abdel-Shafy H, Mansour MSM (2018) Solid waste issue_Sources, composition, disposal, recycling, and valorization. Egypt J Pet 27:12751290

Acharya A, Bastola G, Modi B et al (2021) The impact of COVID-19 outbreak and perceptions of people towards household waste management chain in Nepal. Geoenviron Dis 8:1-11

Ahorsu DK, Lin C-Y, Imani V, Saffari M, Griffiths MD, Pakpour AH (2020) The fear of COVID-19 scale: development and initial validation. Int J Ment Heal Addict:1-9. https://doi.org/10.1007/s11469020-00270-8

Ajzen I (1991) The theory of planned behavior. Organ Behav Hum Decis Process 50:179-211. https://doi.org/10.1922/CDH 2120VandenBroucke08

Alghamdi A, Karpinski AC, Lepp A, Barkley J (2020) Online and faceto-face classroom multitasking and academic performance: moderated mediation with self-efficacy for self-regulated learning and gender. Comput Hum Behav 102:214-222. https://doi.org/10.1016/j. chb.2019.08.018

Al-Sabbagh MQ, Al-Ani A, Mafrachi B et al (2021) Predictors of adherence with home quarantine during COVID-19 crisis: the case of health belief model. Psychol Health Med:1-13. https://doi.org/10. 1080/13548506.2021.1871770

Bandura A (1978) Self-efficacy: toward a unifying theory of behavioral change. Adv Behav Res Ther 1:139-161

Bao Y, Sun Y, Meng S, Shi J, Lu L (2020) 2019-nCoV epidemic: address mental health care to empower society. Lancet 395:e37-e38. https:// doi.org/10.1016/S0140-6736(20)30309-3

Baron RM, Kenny DA (1986) The moderator-mediator variable distinction in social psychological research: Conceptual, strategic, and statistical considerations. J Pers Soc Psychol 51:1173-1182. https:// doi.org/10.1037/0022-3514.51.6.1173

Behera BC (2021) Challenges in handling COVID-19 waste and its management mechanism: a review. Environ Nanotechnol, Monit Manag 15:100432

Bogale D, Kumie A, Tefera W (2014) Assessment of occupational injuries among Addis Ababa city municipal solid waste collectors: a cross-sectional study. BMC Public Health 14. https://doi.org/10. 1186/1471-2458-14-169

Boswell C, Ed D, Long AJ et al (2019) Self-efficacy: changing the tide of evidence-based practice. Worldviews Evidence-Based Nurs 17: 129-135. https://doi.org/10.1111/wvn.12434

Brislin RW (1970) Back-translation for cross-cultural research. J CrossCult Psychol 1:185-216. https://doi.org/10.1177/ 135910457000100301

Bruton GD, Ahlstrom D, Li HL (2010) Institutional theory and entrepreneurship: where are we now and where do we need to move in the future? Entrep Theory Pract 34:421-440. https://doi.org/10.1111/j. 1540-6520.2010.00390.x

Cabinet Office (2021) Guidance: children of critical workers and vulnerable children who can access schools or educational settings. In: GOV.UK
Capoor MR, Parida A (2021) Current perspectives of biomedical waste management in context of COVID-19. Indian J Med Microbiol 39: 171-178. https://doi.org/10.1016/j.ijmmb.2021.03.003

Carico R"R" Jr, Sheppard J, Thomas CB (2021) Community pharmacists and communication in the time of COVID-19: applying the health belief model. Res Soc Adm Pharm 17:1984-1987

Carpenter CJ (2010) A meta-analysis of the effectiveness of health belief model variables in predicting behavior. Health Commun 25:661669. https://doi.org/10.1080/10410236.2010.521906

Champion VL (1999) Revised susceptibility, benefits, and barriers scale for mammography screening. Res Nurs Health 22:341-348. https:// doi.org/10.1002/(sici)1098-240x(199908)22:4<341::aidnur8>3.3.co;2-g

Champion VL, Skinner CS (2003) Differences in perceptions of risk, benefits, and barriers by stage of mammography adoption. J Women's Health 12:277-286. https://doi.org/10.1089/ 154099903321667618

Champion V, Skinner C (2008) The health belief model-theory, research, and practice. In: Glanz K, Rimer BK, Viswanath K, Orleans CT (eds) Health behavior and health education, 4th edn. Jossey-Bass, San Francisco, CA, pp 45-65

Chen YS, Chang CH, Yeh SL, Cheng HI (2015) Green shared vision and green creativity: the mediation roles of green mindfulness and green self-efficacy. Qual Quant 49:1169-1184. https://doi.org/10.1007/ s11135-014-0041-8

Davis LF, Ramirez-Andreotta MD, McLain JET, Kilungo A, Abrell L, Buxner S (2018) Increasing environmental health literacy through contextual learning in communities at risk. Int J Environ Res Public Health 15. https://doi.org/10.3390/ijerph15102203

De Houwer J, Barnes-Holmes D, Moors A (2013) What is learning? On the nature and merits of a functional definition of learning. Psychon Bull Rev 20:631-642. https://doi.org/10.3758/s13423-013-0386-3

Del Villar OAE, Montañez-Alvarado P, Gutiérrez-Vega M et al (2017) Factor structure and internal reliability of an exercise health belief model scale in a Mexican population. BMC Public Health 17:1-9. https://doi.org/10.1186/s12889-017-4150-x

Didarloo A, Nabilou B, Khalkhali HR (2017) Psychosocial predictors of breast self-examination behavior among female students: an application of the health belief model using logistic regression. BMC Public Health 17:1-8. https://doi.org/10.1186/s12889-017-4880-9

DiMaggio PJ, Powell WW (1991) Introducation. In: Powell WW, DiMaggio PJ (eds) The new institutionalism in organizational analysis. University of Chicago Press, $p$ University of Chicago Press

Eller LS, Lev EL, Yuan C, Watkins AV (2016) Describing self-care selfefficacy: definition, measurement, outcomes, and implications. Int J Nurs Knowl:1-11

Eskezia D, Aderaw Z, Ahmed KY, Tadese F (2016) Prevalence and associated factors of occupational injuries among municipal solid waste collectors in four zones of Amhara region, Northwest Ethiopia. BMC Public Health 16:1-7. https://doi.org/10.1186/ s12889-016-3483-1

Fallah Zavareh M, Mohamadi Hezaveh A, Nordfjærn T (2018) Intention to use bicycle helmet as explained by the Health Belief Model, comparative optimism and risk perception in an Iranian sample. Transp Res Part F Traffic Psychol Behav 54:248-263. https://doi. org/10.1016/j.trf.2018.02.003

Fanelli D, Piazza F (2020) Analysis and forecast of COVID-19 spreading in China, Italy and France. Chaos, Solitons Fractals 134:109761. https://doi.org/10.1016/j.chaos.2020.109761

Furnham A, Tu BL, Swami V (2012) Cross-cultural differences in selfassessed intelligence: a comparison of British and Chinese undergraduates. Psychologia 55:21-27. https://doi.org/10.2117/psysoc. 2012.21

Gabriel EH, Hoch MC, Cramer RJ (2019) Health belief model scale and theory of planned behavior scale to assess attitudes and perceptions of injury prevention program participation: An exploratory factor 
analysis. J Sci Med Sport 22:544-549. https://doi.org/10.1016/j. jsams.2018.11.004

Ganguly RK, Chakraborty SK (2021) Integrated approach in municipal solid waste management in COVID-19 pandemic: perspectives of a developing country like India in a global scenario. Case Stud Chem Environ Eng 3:1-8. https://doi.org/10.1016/j.cscee.2021.100087

General Office of the State Council (2013) Guidelines of the General Office of the State Council on the Government's Purchase of Services from social Forces. In: Gen. Off. State Counc. People's Repub. China

Griffiths MD, Gundry LK, Kickul JR (2013) The socio-political, economic, and cultural determinants of social entrepreneurship activity: an empirical examination. J Small Bus Enterp Dev 20:341-357. https://doi.org/10.1108/14626001311326761

Hair JF, Black WC, Babin BJ, Anderson RE. (2010) Multivariate Data Analysis, 7th edn

Hanel PHP, Mehler DMA (2019) Beyond reporting statistical significance : identifying informative effect sizes to improve scientific communication. https://doi.org/10.1177/0963662519834193

Hantoko D, Li X, Pariatamby A, Yoshikawa K (2021) Challenges and practices on waste management and disposal during COVID-19 pandemic. J Environ Manag 286:112140. https://doi.org/10.1016/j. jenvman.2021.112140

Haque MS, Uddin S, Sayem SM, Mohib KM (2021) Coronavirus disease 2019 (COVID-19) induced waste scenario: a short overview. Biochem Pharmacol 9:1-29. https://doi.org/10.1016/j.jece.2020. 104660

Hassan MK, Djajadikerta HG, Choudhury T, Kamran M (2021) Safe havens in Islamic financial markets: COVID-19 versus GFC. Glob Financ J 100643:100643. https://doi.org/10.1016/J.GFJ.2021. 100643

Henseler J (2017) ADANCO 2.0.1 : User Manual. Kleve, Germany

Henseler J, Ringle CM, Sarstedt M (2014) A new criterion for assessing discriminant validity in variance-based structural equation modeling. J Acad Mark Sci 43:115-135. https://doi.org/10.1007/s11747014-0403-8

Higley KA (2017) Education vs. Training: Does it Matter? Health Phys 112:165-171. https://doi.org/10.1097/HP.0000000000000622

Hu Y, Wang Y, Liang H, Chen Y (2017) Seasonal influenza vaccine acceptance among pregnant women in zhejiang province, china: evidence based on health belief model. Int J Environ Res Public Health 14:1551. https://doi.org/10.3390/ijerph14121551

Huang M (2012) Privatization of Urban Environmental Sanitation Services

ISCED (2011) Education. In: UNESCO Inst. Stat.

ISWA (2020) Covid-19: protecting waste workers, maintaining regular waste collection. In: Int. Solid Waste Assoc

Jacob ME, Simkin-silverman LR, Albert SM et al (2016) The preventive services use self-efficacy(PRESS)scale in older women: development and psychometric properties. BMC Health Serv Res 16:110. https://doi.org/10.1186/s12913-016-1321-x

Janmaimool P (2017) Application of protection motivation theory to investigate sustainable waste management behaviors. Sustain 9:1-16. https://doi.org/10.3390/su9071079

Janz NK, Becker MH (1984) The health belief model: a decade later. Health Educ Q 11:1-47

Jeong JY, Ham S (2018) Application of the health belief model to customers' use of menu labels in restaurants. Appetite 123:208-215. https://doi.org/10.1016/j.appet.2017.12.012

Jones CL, Jensen JD, Scherr CL, Brown NR, Christy K, Weaver J (2015) The health belief model as an explanatory framework in communication research: exploring parallel, serial, and moderated mediation. Health Commun 30:566-576. https://doi.org/10.1080/10410236. 2013.873363

Jose R, Narendran M, Bindu A, Beevi N, L M, Benny PV (2021) Public perception and preparedness for the pandemic COVID 19: A Health
Belief Model approach. Clin Epidemiol Glob Heal 9:41-46. https:// doi.org/10.1016/j.cegh.2020.06.009

Kaim A, Ja E, Siman-tov M et al (2020) Impact of a brief educational intervention on knowledge, perceived knowledge, perceived safety, and resilience of the public during COVID-19 crisis Arielle. Int J Environ Res Public Health 17:5971

Kampf G, Todt D, Pfaender S, Steinmann E (2020) Persistence of coronaviruses on inanimate surfaces and its inactivation with biocidal agents. J Hosp Infect 104:246-251. https://doi.org/10.1016/j. jhin.2020.01.022

Keren F, Siddiquei AN, Anwar MA, Asmi F, Ye Q (2021) What explains natives and sojourners preventive health behavior in a pandemic: role of media and scientific self-efficacy. Front Psychol 12. https:// doi.org/10.3389/fpsyg.2021.664399

Khan F, Ahmed W, Najmi A (2019) Understanding consumers' behavior intentions towards dealing with the plastic waste: perspective of a developing country. Resour Conserv Recycl 142:49-58. https://doi. org/10.1016/j.resconrec.2018.11.020

Khoramabadi M, Dolatian M, Hajian S, Zamanian M, Taheripanah R, Sheikhan Z, Mahmoodi Z, Seyedi-Moghadam A (2016) Effects of education based on health belief model on dietary behaviors of Iranian pregnant women. Global J Health Sci 8:230-239. https:// doi.org/10.5539/gjhs.v8n2p230

Kinateder H, Campbell R, Choudhury T (2021) Safe haven in GFC versus COVID-19: 100 turbulent days in the financial markets. Financ Res Lett 101951:101951. https://doi.org/10.1016/J.FRL.2021. 101951

Kocoglu-Tanyer D, Dengiz KS, Sacikara Z (2020) Development and psychometric properties of the public attitude towards vaccination scale-health belief model. J Adv Nurs 76:1458-1468. https://doi. org/10.1111/jan. 14349

Kouassi DP, Coulibaly D, Foster L, Kadjo H, N'Zussuouo T, Traoré Y, Chérif D, N'gattia AK, Thompson MG (2012) Vulnerable groups within a vulnerable population: awareness of the A(H1N1)pdm09 pandemic and willingness to be vaccinated among pregnant women in Ivory Coast. J Infect Dis 206(Suppl):S114-S120. https://doi.org/ 10.1093/infdis/jis532

Kröninger-Jungaberle H, Grevenstein D (2013) Development of salutogenetic factors in mental health - Antonovsky's sense of coherence and Bandura's self-efficacy related to Derogatis' symptom check list (SCL-90-R). Health Qual Life Outcomes 11:1-9. https:// doi.org/10.1186/1477-7525-11-80

Kwon HJ, Ahn M (2019) Boomers' intention to choose healthy housing materials: an application of the Health Belief Model. Sustain 11:113. https://doi.org/10.3390/su11184869

Larowe LR, Rother Y, Powers JM et al (2020) Pain self-efficacy, race, and motivation to quit smoking among persons living with HIV (PLWH). Addict Behav 105:106318. https://doi.org/10.1016/j. addbeh.2020.106318

Lee CK, Corte C, Stein KF, Feng JY, Liao LL (2020) Alcohol-related cognitive mechanisms underlying adolescent alcohol use and alcohol problems: outcome expectancy, self-schema, and self-efficacy. Addict Behav 105:106349. https://doi.org/10.1016/j.addbeh.2020. 106349

Li S (2014) Urban sanitation services outsourcing contract status, problems and strategy in China

Li Y (2019) Public service reform: marketization, semi-marketization and anti-marketization. Shanghai Urban Manag 1:88-91. https://doi.org/ 10.3969/j.issn.1674-7739.2019.01.016

Li W, Liao J, Li Q et al (2020) Public health education for parents during the outbreak of COVID-19: a rapid review. Ann Transl Med 8:628

Ma J, Hipel KW, Hanson ML, Cai X, Liu Y (2018) An analysis of influencing factors on municipal solid waste source-separated collection behavior in Guilin, China by Using the Theory of Planned Behavior. Sustain Cities Soc 37:336-343. https://doi.org/10.1016/j. scs.2017.11.037 
Mackert M, Ball J, Lopez N (2011) Health literacy awareness training for healthcare workers: improving knowledge and intentions to use clear communication techniques. Patient Educ Couns 85:e225e228. https://doi.org/10.1016/j.pec.2011.02.022

Madsen AM, Alwan T, Ørberg A, Uhrbrand K, Jørgensen MB (2016) Waste workers' exposure to airborne fungal and bacterial species in the truck cab and during waste collection. Ann Occup Hyg 60:651668. https://doi.org/10.1093/annhyg/mew021

Mian A, Khan S (2020) Coronavirus: the spread of misinformation. BMC Med 18:18-19. https://doi.org/10.1186/s12916-020-01556-3

Mirzaei-Alavijeh M, Jalilian F, Dragoi EN, Pirouzeh R, Solaimanizadeh L, Khashij S (2020) Self-care behaviors related to air pollution protection questionnaire: a psychometric analysis. Arch Public Heal 78: 1-8. https://doi.org/10.1186/s13690-020-00400-7

Mo PKH, Wong CHW, Lam EHK (2019) Can the health belief model and moral responsibility explain influenza vaccination uptake among nurses? J Adv Nurs 75:1188-1206. https://doi.org/10.1111/ jan.13894

Mol MPG, Pereira AF, Greco DB, Cairncross S, Heller L (2017) Assessment of work-related accidents associated with waste handling in Belo Horizonte (Brazil). Waste Manag Res 35:10841092. https://doi.org/10.1177/0734242X17722209

Morony S, Lamph E, Muscat D, Nutbeam D, Dhillon HM, Shepherd H, Smith S, Khan A, Osborne J, Meshreky W, Luxford K, Hayen A, McCaffery KJ (2018) Improving health literacy through adult basic education in Australia. Health Promot Int 33:867-877. https://doi. org/10.1093/heapro/dax028

Nghiem LD, Morgan B, Donner E, Short MD (2020) The COVID-19 pandemic : considerations for the waste and wastewater services sector. Case Stud Chem Environ Eng 1:1-5. https://doi.org/10. 1016/j.cscee.2020.100006

Nietfeld JL, Cao L, Osborne JW (2006) The effect of distributed monitoring exercises and feedback on performance, monitoring accuracy, and self-efficacy. Metacogn Learn 1:159-179. https://doi.org/10. 1007/s10409-006-9595-6

North DC (1990) Institutions, Institutional Change and Economic Performance. Cambridge University Press, Cambridge

Penteado CSG, Marco AS d C (2021) Covid-19 effects on municipal solid waste management: what can effectively be done in the Brazilian scenario? Resour Conserv Recycl 164:1-9. https://doi. org/10.1016/j.resconrec.2020.105152

Preacher KJ, Hayes AF (2008) Asymptotic and resampling strategies for assessing and comparing indirect effects in multiple mediator models. Behav Res Methods 40:879-891. https://doi.org/10.3758/ BRM.40.3.879

Radisic S, Newbold KB, Eyles J, Williams A (2016) Factors influencing health behaviours in response to the air quality health index: a crosssectional study in Hamilton, Canada. Environ Heal Rev 59:17-29. https://doi.org/10.5864/d2016-002

Rajkumar RP (2020) COVID-19 and mental health: a review of the existing literature. Asian J Psychiatr 52:102066. https://doi.org/10. 1016/j.ajp.2020.102066

Razmara A, Aghamolaei T, Madani A, Hosseini Z, Zare S (2018) Prediction of safe driving behaviours based on health belief model: the case of taxi drivers in Bandar Abbas, Iran. BMC Public Health 18:1-8. https://doi.org/10.1186/s12889-018-5300-5

Richter A, Ng KTW, Vu HL, Kabir G (2021) Waste disposal characteristics and data variability in a mid-sized Canadian city during COVID-19. Waste Manag 122:49-54. https://doi.org/10.1016/j. wasman.2021.01.004

Rosenstock IM (1966) Why people use health services. Milbank Mem Fund Q 44:1-32

Rosenstock IM (1974) Historical origins of the health belief model. Health Educ Monogr 2:328-335
Rosenstock IM, Strecher VJ, Becker MH (1988) Social learning theory and the health belief model. Health Educ Behav 15:175-183. https:// doi.org/10.1177/109019818801500203

Salve PS, Chokhandre P, Bansod DW (2020) Multiple morbidities and health conditions of waste-loaders in Mumbai: a study of the burden of disease and health expenditure. Arch Environ Occup Health 75: 79-87. https://doi.org/10.1080/19338244.2019.1568223

SCIO (2020) Press Conference of the Joint Prevention and Control Mechanism of the State Council on Apirl 12. In: State Counc. Inf. Off. People's Repub. China

Scott WR (2002) The changing world of chinese enterprise: an institutional perspective. In: Tsui AS, Lau C-M (eds) The Management of Enterprises in the People's Republic of China. Springer US, Boston, MA, pp 59-78

Scott WR (2008) Institutions and organizations: ideas and interests. SAGE Publications Ltd, Thousand Oaks

Seelos C, Mair J, Battilana J, Tina Dacin M (2011) The embeddedness of social entrepreneurship: understanding variation across local communities. Emerald Group Publishing Ltd

Shi H, Wang S, Zhao D (2017) Exploring urban resident's vehicular PM2.5 reduction behavior intention: an application of the extended theory of planned behavior. J Clean Prod 147:603-613. https://doi. org/10.1016/j.jclepro.2017.01.108

Shin DS, Park MH, Jeong BY (2019) Structural equation modeling of work-related conditions on safety perception and safety education in waste and recycling collectors. Waste Manag Res 37:717-722. https://doi.org/10.1177/0734242X19854126

Siddiqui TR, Ghazal S, Bibi S, Ahmed W, Sajjad SF (2016) Use of the health belief model for the assessment of public knowledge and household preventive practices in Karachi, Pakistan, a dengueendemic city. PLoS Negl Trop Dis 10:1-15. https://doi.org/10. 1371/journal.pntd.0005129

Somville F, Vanspringel G, De Cauwer H et al (2021) Work stress-related problems in physicians in the time of COVID-19. Int J Occup Med Environ Health 34:1-11

Straub CL, Leahy JE (2014) Application of a modified health belief model to the pro-environmental behavior of private well water testing. J Am Water Resour Assoc 50:1515-1526. https://doi.org/10. 1111/jawr.12217

Tajeri Moghadam M, Raheli H, Zarifian S, Yazdanpanah M (2020) The power of the health belief model (HBM) to predict water demand management: a case study of farmers' water conservation in Iran. J Environ Manag 263:110388. https://doi.org/10.1016/j.jenvman. 2020.110388

Tasi FM, Bui T, Tseng M, Wu K (2020) A causal municipal solid waste management model for sustainable cities in Vietnam under uncertainty: a comparison. Resour Conserv Recycl 154:1-13. https://doi. org/10.1016/j.resconrec.2019.104599

Taylor KM, Betz NE (1983) Applications of self-efficacy theory to the understanding and treatment of career indecision. J Vocat Behav 22: 63-81. https://doi.org/10.1016/0001-8791(83)90006-4

Tencent (2020) Epidemic prevention in the process of easy to be ignored: Beijing waste collectors protection situation survey. In: Tencent

Thakur P, Ganguly R, Dhulia A (2018) Occupational health hazard exposure among municipal solid waste workers in Himachal Pradesh, India. Waste Manag 78:483-489. https://doi.org/10.1016/j.wasman. 2018.06.020

Torkashvand J, Jafari AJ, Godini K et al (2021) Municipal solid waste management during COVID-19 pandemic: a comparison between the current activities and guidelines. J Environ Health Sci Eng 19: 173-179

Travaglio M, Yu Y, Popovic R, Selley L, Leal NS, Martins LM (2021) Links between air pollution and COVID-19 in England. Environ Pollut 268:115859. https://doi.org/10.1016/j.envpol.2020.115859

UNESCO-UIS (2016) Institutional information. In: UNESCO Inst. Stat. 
Urban B, Kujinga L (2017) The institutional environment and social entrepreneurship intentions. Int J Entrep Behav Res 23:638-655. https://doi.org/10.1108/IJEBR-07-2016-0218

Valdez ME, Richardson J (2013) Institutional determinants of macrolevel entrepreneurship. Entrep Theory Pract 37:1149-1175. https:// doi.org/10.1111/etap.12000

Valizadeh J, Mozafari P (2021) A novel cooperative model in the collection of infectious waste in COVID-19 pandemic. J Model Manag ahead-of-print. https://doi.org/10.1108/JM2-07-2020-0189

Vaverková MD, O'Kelly BC, Paleologos EK et al (2021) Municipal solid waste management under Covid-19: challenges and recommendations. Environ Geotech 8:217-232

Wang S, Hsu IC (2014) The effect of role ambiguity on task performance through self-efficacy-a contingency perspective. IEEE Trans Eng Manag 61:681-689. https://doi.org/10.1109/TEM.2014.2356341

Wang Z, Dong X, Yin J (2018) Antecedents of urban residents' separate collection intentions for household solid waste and their willingness to pay: evidence from China. J Clean Prod 173:256-264. https://doi. org/10.1016/j.jclepro.2016.09.223

Wei W (2017) Why waste collectors is a high-risk occupation in China? In: Tencent

Wen F, Zhu J, Ye H, Li LY, Ma Z, Wen XX, Zuo B (2021) Associations between insecurity and stress among Chinese university students: the mediating effects of hope and self-efficacy. J Affect Disord 281: 447-453. https://doi.org/10.1016/j.jad.2020.12.047

White AM, DeCuir-Gunby JT, Kim S (2019) A mixed methods exploration of the relationships between the racial identity, science identity, science self-efficacy, and science achievement of African American students at HBCUs. Contemp Educ Psychol 57:54-71. https://doi. org/10.1016/j.cedpsych.2018.11.006

WHO (2020) WHO Director-General's remarks at the media briefing on 2019-nCoV on 11 February 2020. In: World Heal. Organ

Wu S-I, Chen J-Y (2014) A model of green consumption behavior constructed by the theory of planned behavior. Int J Mark Stud 6:119 132. https://doi.org/10.5539/ijms.v6n5p119

Wu X, Ma W, Velichkova R et al (2019) Environmental, energy, and economic analysis of integrated treatment of municipal solid waste and sewage sludge: a case study in China. Sci Total Environ 647: 1433-1443. https://doi.org/10.1016/j.scitotenv.2018.08.104

Ye Q, Anwar MA, Zhou R, Asmi F, Ahmad I (2020a) Short stay, long impact: ecological footprints of sojourners. Environ Sci Pollut Res 27:11797-11808. https://doi.org/10.1007/s11356-020-07700-z

Ye Q, Anwar MA, Zhou R, Asmi F, Ahmad I (2020b) China's green future and household solid waste: challenges and prospects. Waste Manag 105:328-338. https://doi.org/10.1016/j.wasman.2020.02. 025
Yousefi M, Oskoei V, Jafari AJ et al (2021) Municipal solid waste management during COVID-19 pandemic: effects and repercussions. Environ Sci Pollut Res 28:32200-32209

Yue S, Zhang J, Cao M, Chen B (2020) Knowledge, attitudes and practices of COVID-19 among urban and rural residents in China: a cross-sectional study. J Community Health 46:3-8. https://doi.org/ 10.1007/s10900-020-00877-x

Yuen KF, Li KX, Ma F, Wang X (2020) The effect of emotional appeal on seafarers' safety behaviour: an extended health belief model. J Transp Health 16:100810. https://doi.org/10.1016/j.jth.2019. 100810

Zandifar A, Badrfam R (2020) Iranian mental health during the COVID19 epidemic. Asian J Psychiatr 51:101990. https://doi.org/10.1016/j. ajp. 2020.101990

Zhang B, Hung LK, Wang B, Wang Z (2019) From intention to action: how do personal attitudes, facilities accessibility, and government stimulus matter for household waste sorting? J Environ Manage 233:447-458. https://doi.org/10.1016/j.jenvman.2018.12.059

Zheng J, Zhang Y, Xu Y et al (2020) Health literacy and demand for health education on novel coronavirus pneumonia epidemic among community residents in Fujian province : an online survey during epidemic outbreak. Chin J Public Heal 36:160-164. https://doi.org/ 10.11847/zgggws 1128092

Zhong B, Luo W, Li H et al (2020) Knowledge,attitudes,and practices towards COVID-19 among Chinese residents during the rapid rise period of the COVID-19 outbreak: a quick online cross-sectional survey. Int J Biol Sci 16:1745-1752. https://doi.org/10.7150/ijbs. 45221

Ziaei M, Choobineh A, Abdoli-Eeamaki M, Ghaem H (2018) Individual, physical, and organizational risk factors for musculoskeletal disorders among municipality solid waste collectors in Shiraz, Iran. Ind Health 56:308-319

Ziaei M, Choobineh A, Abdoli-Eramaki M, Ghaem H, Jaberi O (2019) Psychological and physical job demands, decision latitude, and work-related social support among Iranian waste collectors. Waste Manag 95:377-387. https://doi.org/10.1016/j.wasman.2019.06.031

Zolnikov TR, da Silva RC, Tuesta AA, Marques CP, Cruvinel VRN (2018) Ineffective waste site closures in Brazil : a systematic review on continuing health conditions and occupational hazards of waste collectors. Waste Manag 80:26-39. https://doi.org/10.1016/j. wasman.2018.08.047

Zulfiqar S, Asmi F (2019) Opportunity recognition and readiness of youth towards social entrepreneurship. Entrep Res J

Publisher's note Springer Nature remains neutral with regard to jurisdictional claims in published maps and institutional affiliations. 